\title{
Expanding the taxonomic conundrum: Three new species of groundwater crustacean (Syncarida, Bathynellacea, Parabathynellidae) endemic to the Iberian Peninsula
}

\author{
ANA ISABEL CAMACHO \\ Museo Nacional de Ciencias Naturales, Madrid, Spain
}

(Accepted 16 November 2004)

\begin{abstract}
Two new species of the genus Iberobathynella and one new species of the cosmopolitan genus Hexabathynella are described from the Iberian Peninsula. The three new species were found in the groundwater of caves and the gravelly bank of a river, two species in the north of Spain (Cantabria and Burgos) and one in the south (Sevilla). The two new species of the genus Iberobathynella present a unique combination of characters. These character combinations for the species from Cantabria are: thoracopod 8 female with wrinkled cuticle and two teeth; seven spines on the furca; nine spines on the sympod, three barbed and one plumose seta on the exopod and two barbed setae on the endopod of the uropod; maxilla with 0,0 and 15 setae on the three segments, respectively; five teeth on the pars incisiva and six teeth on the pars molaris of the mandible and seven segments on the antennule. The combinations of characters for the species from Burgos are: antennule with seven segments; segment 5 of the antennule with one aesthetasc; mandible with four and five teeth on the pars incisiva and pars molaris respectively; maxillule with one seta on segment 1 and 14 setae on segment 3; segment 1 of the endopod of the thoracopod 1 with two setae; uropod with six spines on the sympod, four barbed setae and one plumose seta on the exopod and no setae on the endopod; furca with five spines and the thoracopod 8 female with wrinkled cuticle and two teeth. This last species has an exclusive character for the genus: the absence of setae on the endopod of the uropod. The new species of the genus Hexabathynella has six spines of similar length on the sympod of the uropod (in all other species within the genus the distal spine is longer than the others); the form of the antennal organ in the males is shown to be a new unique character for the genus; the maxilla has three and 13 setae on segments 2 and 3, respectively; the uropod has six spines on the sympod, three barbed setae on the exopod and two smooth setae on the endopod, the endopod is twice as long as the exopod and the shape of the female thoracopod 8 is unique.
\end{abstract}

Keywords: Cave, Crustacea, groundwater, Hexabathynella, Iberian Peninsula, Iberobathynella, taxonomy

\section{Introduction}

With the discovery of two new species, the tribe Iberobathynellini (Camacho and Serban, 1998) now comprises 25 species on the Iberian Peninsula and four in the rest of the world

Correspondence: Museo Nacional de Ciencias Naturales, José Gutiérrez Abascal 2, 28006 Madrid, Spain. Email: mcnac22@mncn.csic.es

Published 29 April 2005.

ISSN 0022-2933 print/ISSN 1464-5262 online (C) 2005 Taylor \& Francis Group Ltd

DOI: $10.1080 / 00222930400025748$ 
(three in North America and one in North Africa). This makes it the most diverse and most studied group of the family Parabathynellidae (Crustacea, Syncarida, Bathynellacea) in the world (Camacho and Serban 2000; Camacho 2003c).

Of the 18 species of iberobathynells known to date none show the combinations of characters present in the two new species described here. The two new species belong to the genus Iberobathynella Schminke, 1973 (with 20 species) (see Table I), and subgenus Asturibathynella Camacho and Serban, 1998 (with 11 species) and are named $I$. $(A$.) lamasonensis n. sp. (from Cantabria) and I. (A.) cornejoensis n. sp. (from Burgos).

This discovery is also important in the investigation of the group from a phylogenetic point of view. Some of these new combinations of characters give continuity to the range of currently known character series and fill in gaps which are very useful in resolving relationships between species (Camacho et al. 1997; Camacho et al. 2000; Guil and Camacho 2001).

The new species of the genus Hexabathynella Schminke, 1972 is named H. sevillaensis n. sp. This new species is the fourth species of this genus found in Spain. Its discovery is of interest as this is the first time that a species of this genus has been found in a cave. Before this, the 18 species (found in 26 sites throughout the world) (Camacho 2003a, 2004) (see Table II) had only appeared in wells, springs and the gravelly banks of rivers, never in subterranean cave water.

Table I. The species of Iberobathynella Schminke, 1973.

\begin{tabular}{|c|c|c|c|}
\hline Subgenus & Species & Author & Country \\
\hline (Iberobathynella) & & Schminke, 1973 & \\
\hline (Iberobathynella) & lusitanica & (Braga, 1949) & Portugal \\
\hline (Iberobathynella) & barcelensis & (Noodt and Galhano, 1969) & Portugal \\
\hline (Iberobathynella) & valbonensis & (Galhano, 1970) & $\begin{array}{l}\text { Portugal and } \\
\text { Spain }\end{array}$ \\
\hline (Iberobathynella) & gracilipes & (Braga, 1960) & Portugal \\
\hline (Iberobathynella) & paragracilipes & Camacho and Serban, 1998 & Spain \\
\hline (Espanobathynella) & & Camacho and Serban, 1998 & \\
\hline (Espanobathynella) & espaniensis & Serban and Comas i Navarro, 1978 & Spain \\
\hline (Espanobathynella) & cantabriensis & Camacho and Serban, 1998 & Spain \\
\hline (Espanobathynella) & magna & Camacho and Serban, 1998 & Spain \\
\hline (Asturibathynella) & & Camacho and Serban, 1998 & \\
\hline (Asturibathynella) & asturiensis & Serban and Comas i Navarro, 1978 & Spain \\
\hline (Asturibathynella) & parasturiensis & Camacho and Serban, 1998 & Spain \\
\hline (Asturibathynella) & cavadoensis & (Noodt and Galhano, 1969) & $\begin{array}{l}\text { Portugal and } \\
\text { Spain }\end{array}$ \\
\hline (Asturibathynella) & ortizi & Camacho, 1989 & Spain \\
\hline (Asturibathynella) & rouchi & Camacho and Coineau, 1987 & Spain \\
\hline (Asturibathynella) & imuniensis & Camacho, 1987 & Spain \\
\hline (Asturibathynella) & serbani & Camacho, $2003 \mathrm{~b}$ & Portugal \\
\hline (Asturibathynella) & guarenensis & Camacho, 2003b & Spain \\
\hline (Asturibathynella) & celiana & Camacho, 2003b & Spain \\
\hline (Asturibathynella) & lamasonensis $\mathrm{n} . \mathrm{sp}$. & & Spain \\
\hline (Asturibathynella) & cornejoensis n. sp. & & Spain \\
\hline Unknown & pedroi & Camacho, 2003b & Portugal \\
\hline
\end{tabular}


Table II. The species of Hexabathynella Schminke, 1972.

\begin{tabular}{|c|c|c|}
\hline Species & Author & Country \\
\hline H. nicoleiana & Camacho, 1986 & Madrid, Spain \\
\hline H. minuta & (Noodt and Galhano, 1969) & Portugal and Spain \\
\hline H. valdecasasi & Camacho, 2004 & Toledo, Spain \\
\hline H. knoepffleri & (Coineau, 1965) & Corsica, France \\
\hline H. otayana & Cho, 2001 & California, USA \\
\hline H. hessleri & Cho, 2001 & California, USA \\
\hline H. muliebris & Cho, 2001 & California, USA \\
\hline H. pauliani & (Delamare Deboutteville, 1953) & Madagascar \\
\hline H. decora & Schminke, 1973 & New South Wales, Australia \\
\hline H. aotearoae & Schminke, 1973 & Westland, New Zealand \\
\hline H. halophila & Schminke, 1972 & New South Wales, Australia \\
\hline H. hebrica & (Cvetkov and Petrova, 1964) & Plovdiv, Bulgaria \\
\hline H. longiappendiculata & (Cvetkov, 1970b) & Plovdiv, Bulgaria \\
\hline H. tenera & (Cvetkov, 1968) & Sozopol, Bulgaria \\
\hline H. breviappendiculata & (Cvetkov, 1970a) & Bulgaria \\
\hline H. nestica & (Cvetkov, 1970a) & Bulgaria \\
\hline H. szidati & (Noodt, 1965) & Cordoba, Argentina \\
\hline H. paranaensis & (Jakobi, 1972) & Cotinga Island, Brazil \\
\hline H. sevillaensis $\mathrm{n} . \mathrm{sp}$. & & Sevilla, Spain \\
\hline
\end{tabular}

\section{Methods}

The specimens studied were found in five samples obtained from Spain.

The material was collected with a $0.1 \mathrm{~mm}$ mesh hand net (plankton type) from water in caves using the Karaman-Chappuis method (Camacho 1992). For the river bank (interstitial environment) the Bou-Rouch method was used (Camacho 1992).

A complete dissection of all anatomical parts of all type series was made, and kept as permanent preparations (special metal slides, glycerine gelatine stained with methylene blue as the mounting medium). Anatomical examinations were performed using an oil immersion lens $(100 \times)$. The descriptions are based on the type series. The material is deposited in the Museo Nacional de Ciencias Naturales, Madrid (MNCN).

\section{Systematic account}

Genus Iberobathynella Schminke, 1973

Subgenus Asturibathynella Camacho and Serban, 1998

Iberobathynella (Asturibathynella) lamasonensis $\mathrm{n}$. sp.

(Figures 1, 2)

\section{Material examined}

Fuente de la Estragüeña, La Hermida (Cantabria) (coordinates X: 369823, Y: 4795611, Z: $100 \mathrm{~m}$ ) (type locality), collected by PASCALIS team (4 April 2002) (five males, seven females and three juveniles). The details of the new description are all based on adult specimens (five males and seven females). The holotype is a male and the type series contains 14 specimens (paratypes) (MNCN 20.04/5911). 


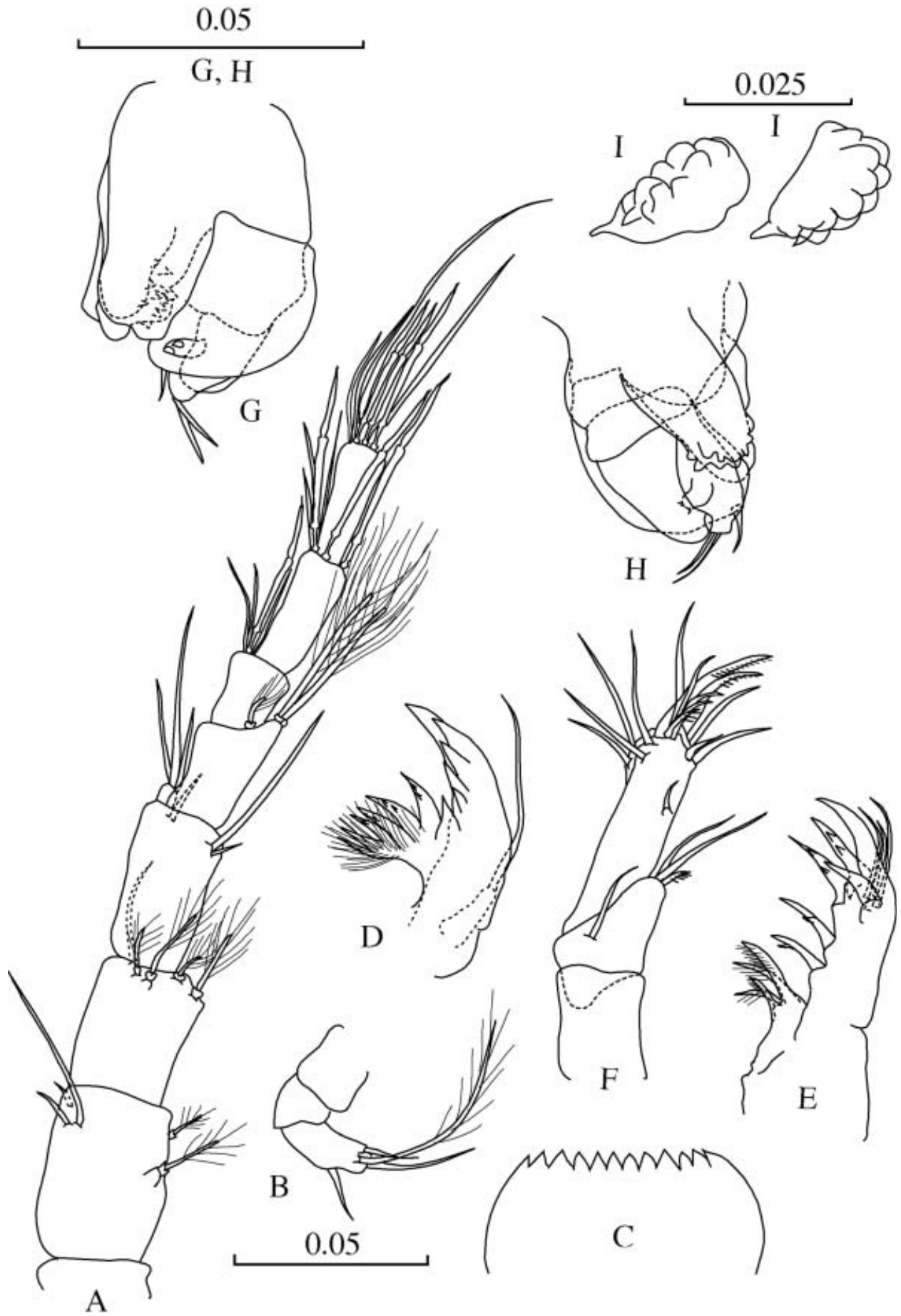

Figure 1. Iberobathynella (Asturibathynella) lamasonensis n. sp., male. (A) Antennule (dorsal view); (B) antenna (ventral view); (C) labrum; (D) mandible; (E) maxillule; (F) maxilla; (G) thoracopod 8 male (latero-internal view); $(\mathrm{H})$ thoracopod 8 male (latero-external view); (I) thoracopod 8 female (ventral view). Scale bars in $\mathrm{mm}$. 

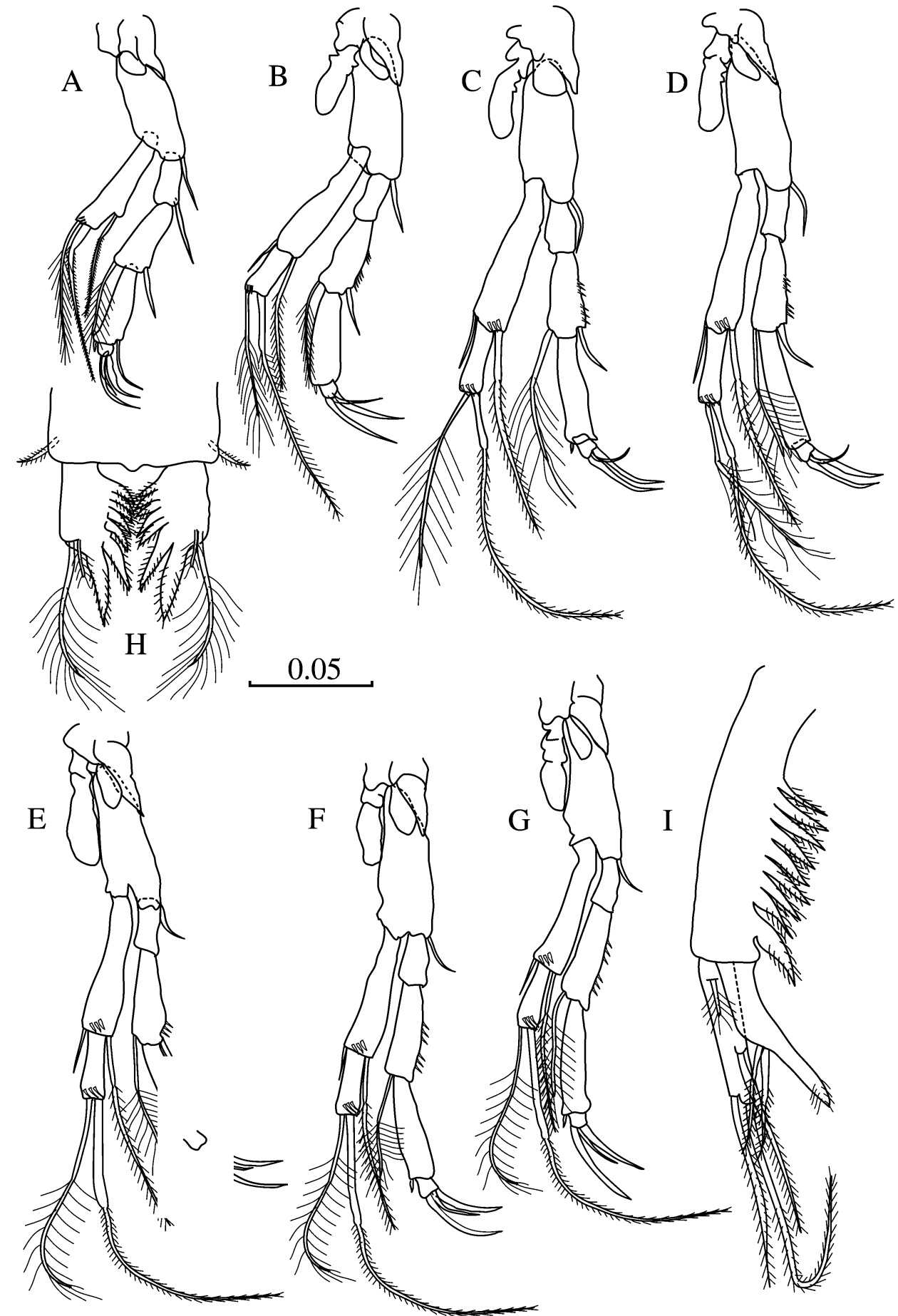

Figure 2. Iberobathynella (Asturibathynella) lamasonensis n. sp., male. (A) Thoracopod 1; (B) thoracopod 2; (C) thoracopod 3; (D) thoracopod 4; (E) thoracopod 5; (F) thoracopod 6; (G) thoracopod 7; (H) pleotelson and furca (dorsal view); (I) uropod (latero-internal view). Scale bar in $\mathrm{mm}$. 


\section{Description}

Body. Total length males 0.95-1.16 (holotype $0.96 \mathrm{~mm}$ ) and of females $1.0-1.1 \mathrm{~mm}$. Body elongated, segments progressively widening towards posterior end of body. Head of similar length and width.

Antennule (Figure 1A). With seven segments; no sexual dimorphism; length of first four segments greater than that of last three; setation as in Figure 1A (segment 5 with one aesthetasc; segments 5 and 6 with three aesthetascs).

Antenna (Figure 1B). Three-segmented, last segment longest, with two smooth and one plumose terminal setae and a small, shorter seta in the middle; first two segments without setae.

Labrum (Figure 1C). With eight main teeth, and two lateral teeth at either end.

Mandible (Figure 1D). Pars incisiva with five well-developed teeth; pars molaris with six teeth, four strong distal and two small joined proximal teeth with a large number of fine setae; mandibular palp does not exceed pars incisiva in length.

Maxillule (Figure 1E). Proximal endite with four claws (spines of different sizes); distal endite with six claws, two smooth and apical, the other four with spines; three subterminal smooth setae on outer distal margin.

Maxilla (Figure 1F). Three-segmented, without setae on basal segment; segment 2 with two long setae and one shorter at the distal end, one additional seta on inner border; segment 3 elongated with 15 setae.

Thoracopods. Thoracopods 1-7 (Figure 2A-G): well developed, length gradually increasing from 1 to 5, last three similar in size; well-developed epipodite on 2-7, not measuring more than half length of basipod; basipod with one lateral, terminal seta. Thoracopod 1 (Figure 2A): short, exopod one-segmented in all completely developed specimens, with three setae (terminal setae one plumose, the other barbed) and with two groups of ctenidia at distal margin of the exopod; endopod four-segmented: segment 1 with one smooth ventral seta, 2 with one smooth and one plumose seta, 3 with two setae, one small and smooth and the other tiny, terminal segment with two claws of different length and one seta. Thoracopods 2-7 (Figure 2B-G): exopod biarticulated, segment 1 with two terminal setae, one short and smooth and one long and barbed; segment 2 with two terminal setae, one barbed, the other plumose; ctenidia at distal margin of the segments; endopod four-segmented, segment 1 short and without setae; 2 with two groups of lateral ctenidia and one plumose and one smooth seta (absent on thoracopod 7 and sometimes on thoracopod 6 also); 3 with one tiny seta; and 4 with one seta and two strong claws of similar length. Thoracopod 8, male (Figure $1 \mathrm{G}, \mathrm{H}$ ): massive, almost square; basal region massive; inner lobe almost square and completely integrated in the basal region, does not exceed the distal end of dentate lobe; dentate lobe with 10-12 teeth; basipod rounded and with one short seta at the end, endopod not very small, with two setae; exopod small with two small teeth; outer lobe not fused with basipod and almost triangular. Thoracopod 8, female paratype (Figure 1I): not very small and with wrinkled cuticle, with one small terminal tooth and another small dorsal tooth.

Dorsal margin of pleotelson (Figure 2I). Anal operculum not pronounced; one barbed seta on lateral side. 
Uropod (Figure 2H). Sympod almost twice the length of endopod and four times longer than wide; with eight barbed spines, the most distal a little longer than the others which are of equal length and located along two-thirds of length; endopod longer than exopod, with two barbed setae of similar length which exceed the distal end of the endopod; exopod with two terminal barbed setae, one subterminal barbed seta and one basal plumose seta.

Furca (Figure 2I). With seven barbed spines (the two terminal ones a little longer and thicker); two dorsal plumose setae, one large and the other shorter.

\section{Etymology}

The species name is derived from the Lamason valley, which is full of caves and different species of the genus Iberobathynella.

\section{Remarks}

The new species belongs to the subgenus $I$. (Asturibathynella) (six teeth on the distal endite of maxillule, amongst other characteristics).

In the new species the thoracopod 8 female has a wrinkled cuticle as in four of the species in the subgenus, I. (A.) rouchi Camacho, 1987, I. (A.) asturiensis Serban and Comas i Navarro, 1978, I. (A.) parasturiensis Camacho and Serban, 1998, and I. (A.) guarenensis Camacho, 2003b (see Table I); with two spines as in the other three species except $I$. $(A$.) guarenensis which only has one; $I$. (A.) parasturiensis and $I$. (A.) asturiensis have a pronounced anal operculum and $I$. (A.) rouchi and $I$. (A.) guarenensis have no pronounced anal operculum, like the new species, although in this new species it is slightly more pronounced. The presence of a single aesthetasc on segment 5 of the antennule indicates a similarity with $I$. (A.) asturiensis and $I$. (A.) parasturiensis, but it is different from them in many other aspects (e.g. the setation on maxilla and mandible) (see Table III). The setation on the maxilla ( 0 setae on the first segment and 15 on the third) and the number and type of setae on the exopod and endopod of the uropod (although in this case the two setae go beyond the distal end of the endopod and in other cases they are shorter), and also the number of spines on the sympod being close to $I$. (A.) guarenensis. The new species has five and six teeth on the pars incisiva and pars distalis, respectively, whereas $I$. (A.) guarenensis has six and five, respectively. In short, it is closest to $I$. (A.) guarenensis, but differs in a character as important as the number of segments of the antennule (six in this species, seven in the new species) and in other details (see Table III). We can be sure this is a new species given that, although it shares some characters with other species of the subgenus, the combination of all characters is unique. The appearance and size of the different lobes of the thoracopod 8 male are also unique.

\section{Iberobathynella (A.) cornejoensis n. $\mathrm{sp.}$}

(Figures 3, 4)

\section{Material examined}

Gravel bank on the Trema stream (26 November 2003) (coordinates X: 448805, Y: 4763430, Z: 638), La Mina cave (26 April 2003) (coordinates X: 448875, Y: 4764802, Z: 
Table III. Taxonomic characters of the different species of the subgenus Iberobathynella (Asturibathynella).

\begin{tabular}{|c|c|c|c|c|c|c|c|c|c|c|c|}
\hline & \multicolumn{11}{|c|}{ Species of the subgenus Iberobathynella (Asturibathynella) } \\
\hline & 1 & 2 & 3 & 4 & 5 & 6 & 7 & 8 & 9 & 10 & 11 \\
\hline \multicolumn{12}{|l|}{ Antennule } \\
\hline No. of segments & 7 & 7 & 7 & 7 & 7 & 7 & 7 & 6 & 6 & 7 & 7 \\
\hline No. of aesthetascs on segment 5 & 1 & 1 & 2 & 2 & 2 & 2 & 1 & - & - & 1 & 1 \\
\hline \multicolumn{12}{|l|}{ Mandible } \\
\hline No. of teeth on pars incisiva & 5 & 4 & 5 & 5 & 7 & 6 & 5 & 6 & - & 5 & 4 \\
\hline No. of teeth on pars molaris & 7 & 5 & 7 & 6 & 7 & 7 & 6 & 5 & - & 6 & 5 \\
\hline \multicolumn{12}{|l|}{ Maxillule } \\
\hline No. of teeth on distal endite & 6 & 6 & 6 & 6 & 6 & 6 & 6 & 6 & 6 & 6 & 6 \\
\hline \multicolumn{12}{|l|}{ Maxilla } \\
\hline No. of setae on segment 1 & 0 & 0 & 0 & 0 & 1 & 1 & 0 & 0 & 1 & 0 & 1 \\
\hline No. of setae on segment 3 & 14 & 14 & 15 & 14 & 16 & 14 & 15 & 15 & 15 & 15 & 14 \\
\hline \multicolumn{12}{|l|}{ Thoracopod 1 endopod } \\
\hline No. of setae on segment 1 & 1 & 2 & 1 & 1 & 2 & 2 & 1 & 1 & 2 & 1 & 2 \\
\hline \multicolumn{12}{|l|}{ Uropod } \\
\hline No. of spines on sympod & 7 & 10 & $5+1$ & $4+1$ & $6+1$ & $7+1$ & $6+1$ & $8+1$ & $4+1$ & $8+1$ & $5+1$ \\
\hline No. of setae on exopod & $3 B+1 P$ & $3 \mathrm{~B}+1 \mathrm{P}$ & $2 \mathrm{~B}+1 \mathrm{P}$ & $3 \mathrm{~B}+1 \mathrm{P}$ & $3 \mathrm{~B}+1 \mathrm{P}$ & $4 \mathrm{~B}+1 \mathrm{P}$ & $2 \mathrm{~B}+1 \mathrm{P}$ & $3 \mathrm{~B}+1 \mathrm{P}$ & $4 \mathrm{~B}+1 \mathrm{P}$ & $3 \mathrm{~B}+1 \mathrm{P}$ & $4 \mathrm{~B}+1 \mathrm{P}$ \\
\hline No. of setae on endopod & $2 \mathrm{~B}$ & $2 \mathrm{~B}$ & $2 \mathrm{~B}$ & $2 \mathrm{~B}$ & $1 \mathrm{~B}+1 \mathrm{P}+1 \mathrm{~S}$ & $1 \mathrm{P}$ & $1 \mathrm{P}$ & $2 \mathrm{~B}$ & $2 \mathrm{~B}+1 \mathrm{P}$ & $2 \mathrm{~B}$ & 0 \\
\hline \multicolumn{12}{|l|}{ Furca } \\
\hline \multirow{2}{*}{\multicolumn{12}{|c|}{ Thoracopod 8 female }} \\
\hline & & & & & & & & & & & \\
\hline Cuticle & $\mathrm{W}$ & W & s & $\mathrm{s}$ & $\mathrm{W}$ & $\mathrm{s}$ & s & $\mathrm{W}$ & - & $\mathrm{W}$ & $\mathrm{s}$ \\
\hline No. of teeth & 2 & 2 & 2 & 2 & 2 & 2 & 2 & 1 & - & 2 & 2 \\
\hline Anal operculum & $\mathrm{Y}$ & $\mathrm{Y}$ & $\mathrm{Y}$ & $\mathrm{Y}$ & $\mathrm{N}$ & $\mathrm{N}$ & $\mathrm{Y}$ & $\mathrm{N}$ & $\mathrm{Y}$ & Y small & Y small \\
\hline
\end{tabular}

1, I. (A.) asturiensis Serban and Comas i Navarro, 1978; 2, I. (A.) parasturiensis Camacho and Serban, 1998; 3, I. (A.) cavadoensis Noodt and Galhano, 1969; 4, I. (A.) ortizi Camacho, 1989; 5, I. (A.) rouchi Camacho and Coineau, 1987; 6, I. (A.) imuniensis Camacho, 1987; 7, I. (A.) serbani; 8, I. (A.) guarenensis; 9, I. (A.) celiana; 10, I. (A.) lamasonensis $\mathrm{n}$. sp.; 11, I. (A.) cornejoensis $\mathrm{n}$. sp. B, barbed; P, plumose; $\mathrm{S}$, smooth; $\mathrm{W}$, wrinkled; $\mathrm{Y}$, pronounced; $\mathrm{N}$, not pronounced. 


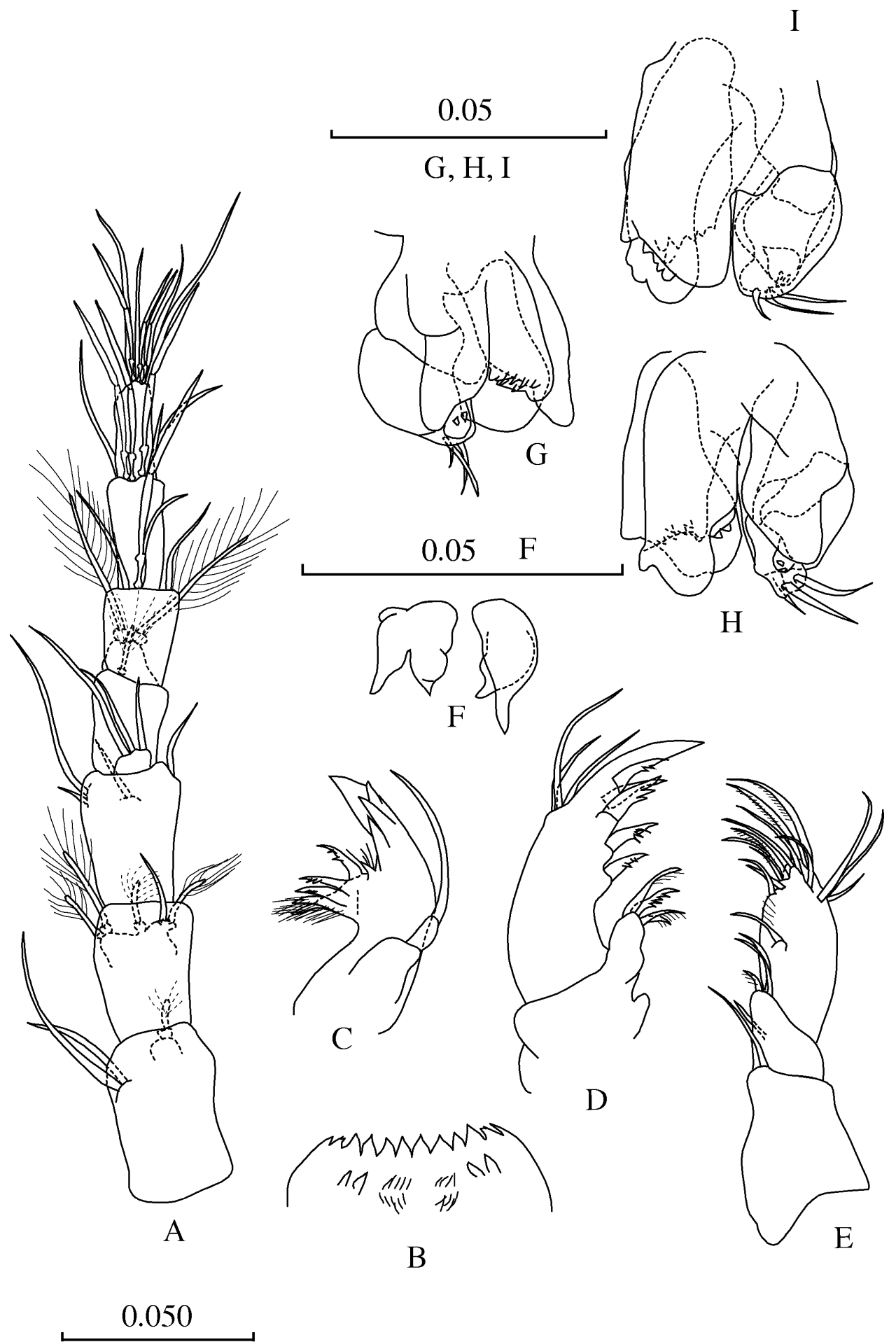

Figure 3. Iberobathynella (Asturibathynella) cornejoensis n. sp., male. (A) Antennule; (B) labrum; (C) mandible; (D) maxillule; (E) maxilla; (F) thoracopod 8 female (dorsal view); (G) thoracopod 8 male (latero-external view); (H) thoracopod 8 male (latero-internal view); (I) thoracopod 8 male (internal view). Scale bars in $\mathrm{mm}$. 


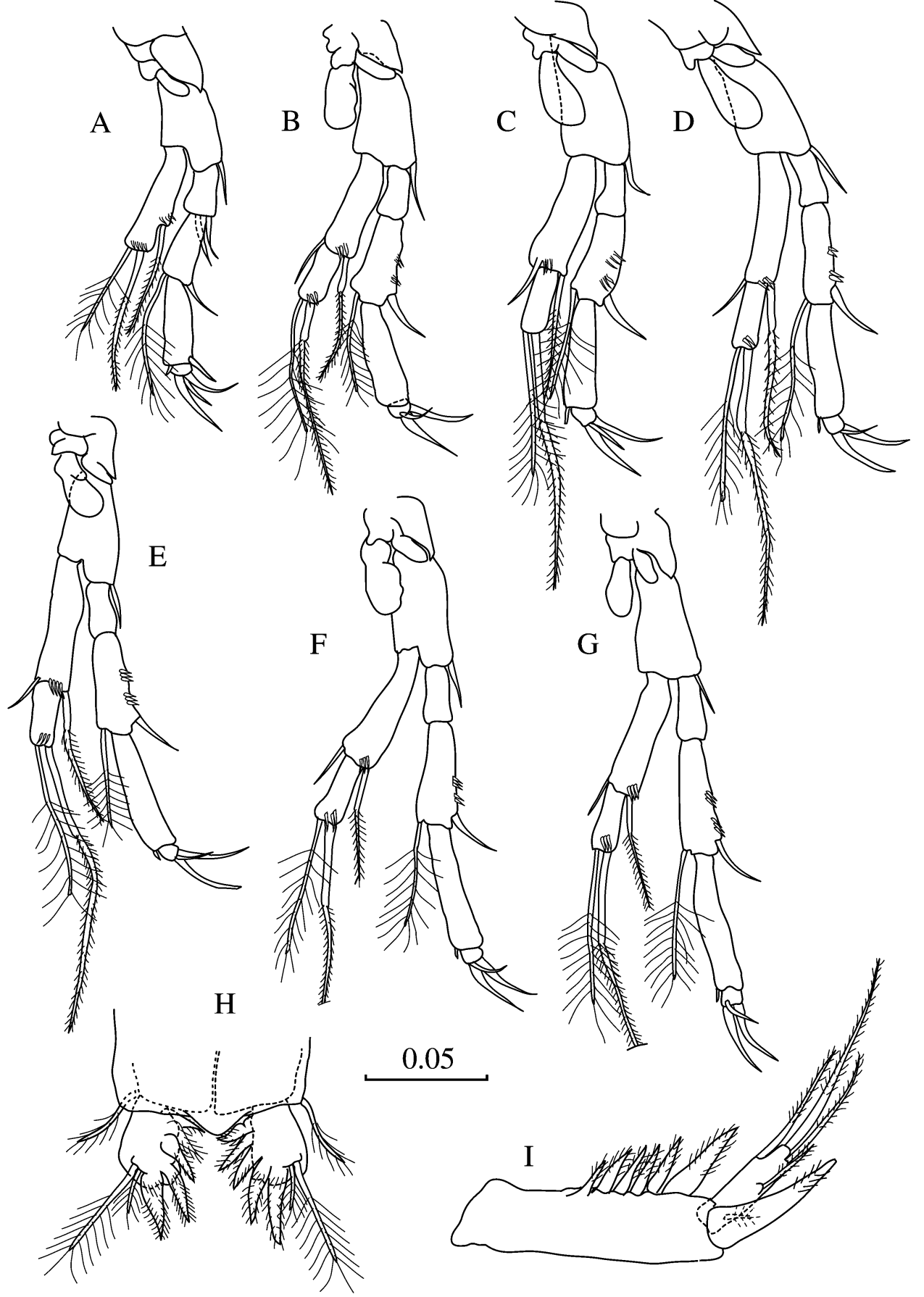

Figure 4. Iberobathynella (Asturibathynella) cornejoensis n. sp., male. (A) Thoracopod 1; (B) thoracopod 2; (C) thoracopod 3; (D) thoracopod 4; (E) thoracopod 5; (F) thoracopod 6; (G) thoracopod 7; (H) pleotelson and furca (dorsal view); (I) uropod (latero-internal view). Scale bar in $\mathrm{mm}$. 
673), and Redonda cave (26 April 2003) (coordinates X: 448858, Y: 4764811, Z: 668) (type locality) all of these in Cornejo (Burgos), collected by PASCALIS team (three males, one juvenile, one female and three juveniles, one female and three males, respectively). All adult specimens were studied. The holotype is a male and the type series contains 10 specimens (paratypes) (MNCN 20.04/5912).

\section{Description}

Body. Total length of males $0.90-1.37 \mathrm{~mm}$ (holotype 1.06) and of females 1.03-1.04. Body elongated, segments progressively lengthening and widening towards posterior end of body. Head of similar length and width.

Antennule (Figure 3A). With seven segments; no sexual dimorphism; length of first three segments equal to length of last four; setation as in Figure 3A (segment 5 with one aesthetasc and segments 6 and 7 with three aesthetascs).

Labrum (Figure 3B). With eight main teeth, and two smaller lateral teeth at either end.

Mandible (Figure 3C). Pars incisiva with four well-developed teeth; pars molaris with five teeth, distal three with denticles, two small joined proximal teeth without denticles but with a large number of fine setae; mandibular palp does not exceed pars incisiva in length.

Maxillule (Figure 3D). Proximal endite with four claws (spines of different sizes); distal endite with six claws, two apical ones smooth, the other four with spines; three subterminal smooth setae on outer distal margin.

Maxilla (Figure 3E). Three-segmented, with one seta on basal segment; segment 2 with two long setae, and one shorter seta at the distal end, one additional seta on inner border; segment 3 elongated with 14 setae.

Thoracopods. Thoracopods 1-7 (Figure 4A-G): well developed, length gradually increasing from 1 to 5, 5-7 similar in size; well-developed epipodite on 2-7, exceeding half length of basipod; basipod with one lateral, smooth, terminal seta. Thoracopod 1 (Figure 4A): short, exopod one-segmented in all completely developed specimens, with three setae (two terminal, one seta plumose and the other barbed), and with one group of ctenidia at distal margin of the exopod; endopod four-segmented: first segment with two smooth dorsal setae, second with one smooth dorsal seta and one plumose ventral seta, third with two setae, one small and smooth, and the fourth, tiny, terminal segment with two claws of similar length and one smooth seta. Thoracopods 2-7 (Figure 4B-G): exopod biarticulated, segment 1 with two terminal setae, one short and smooth and one long and barbed; segment 2 with two terminal setae, one barbed, the other plumose; ctenidia at distal margin of the segments; endopod four-segmented, segment 1 short and without setae; 2 with two groups of lateral ctenidia and one plumose and one smooth seta; 3 with one tiny seta; and 4 with one seta and two strong claws of similar length. Thoracopod 8, female (Figure $3 \mathrm{~F}$ ): not very small, triangular and with smooth cuticle, with two teeth. Thoracopod 8, male (Figure 3G-I): massive, almost square; basal region massive; outer lobe almost triangular not separated from basal region; dentate lobe with 8-12 teeth; basipod rounded and with one short seta at the end, endopod small with two smooth setae of similar size; exopod small; inner lobe not fused with basipod and almost square. 
Dorsal margin of pleotelson (Figure 4H). With anal operculum slightly pronounced, well developed; one plumose seta on lateral side.

Uropod (Figure 4I). Sympod almost twice length of endopod and more than three times longer than wide; with six barbed spines, the most distal longer than the others, which are of equal length and located on the front two-thirds; endopod very slightly longer than exopod, in lancet form, without setae; exopod with four barbed setae (one terminal, one subterminal, and the other two in middle of the exopod) and one small, plumose seta basiventrally.

Furca (Figure 4H). Solid, with five barbed spines (terminal longest); two dorsal plumose setae, one large and the other shorter.

\section{Etymology}

The species is named after the town Cornejo where it was found.

\section{Remarks}

Iberobathynella $(A$.) cornejoensis $\mathrm{n}$. sp. belongs to the subgenus $I$. (Asturibathynella) (six teeth on distal endite of maxillule, amongst other characters). Within this subgenus it belongs to the group of species which have two setae on the endopod of segment 1 of thoracopod 1 , and one seta on segment 1 of the maxilla. This group consists of the species: I. (A.) imuniensis Camacho, 1987, I. (A.) rouchi Camacho and Coineau, 1987 and I. (A.) celiana Camacho 2003b (see Table III). In this subgroup only the species $I$. (A.) imuniensis has 14 setae on segment 3 of the maxilla, like the new species, while the other two species have 16 and 15, respectively.

The species $I$. (A.) imuniensis and $I$. (A.) celiana have four barbed setae on the exopod of the uropod, like the new species, but both have setae (one and three, respectively) on the endopod of the uropod, while the new species has no setae. This is the only case in the whole genus where we find this character. The new species, like $I$. ( $A$.) celiana, has a slightly pronounced anal operculum but $I$. $(A$.) celiana has six segments on the antennule, while the new species has seven (which is the norm in this genus). The female thoracopod 8 in the new species is similar to that of $I$. (A.) imuniensis. The number of spines on the sympod of the uropod is the lowest in the subgenus: most species having more than five. There are only five spines on the furca in the new species; no other species in the subgenus has so few spines. Some of the characters exhibited by the new species are present in other species in the subgenus (see Table III), but the combination of all of them is unique to the new species. Furthermore, the absence of setae on the endopod of the uropod is a unique character, as is the presence of only five spines on the furca. From the total characters combination as well as these two characters we can say that $I$. (A.) cornejoensis $\mathrm{n}$. sp. is without doubt a new species.

\section{Hexabathynella sevillaensis $\mathrm{n} . \mathrm{sp}$.}

(Figures 5, 6)

\section{Material examined}

Santiago El Grande cave (Constantina, Sevilla Province, Spain), collected by Alberto Tinaut (27 August 2002) and Antonio G. Valdecasas and Jaime Rodriguez (17 October 


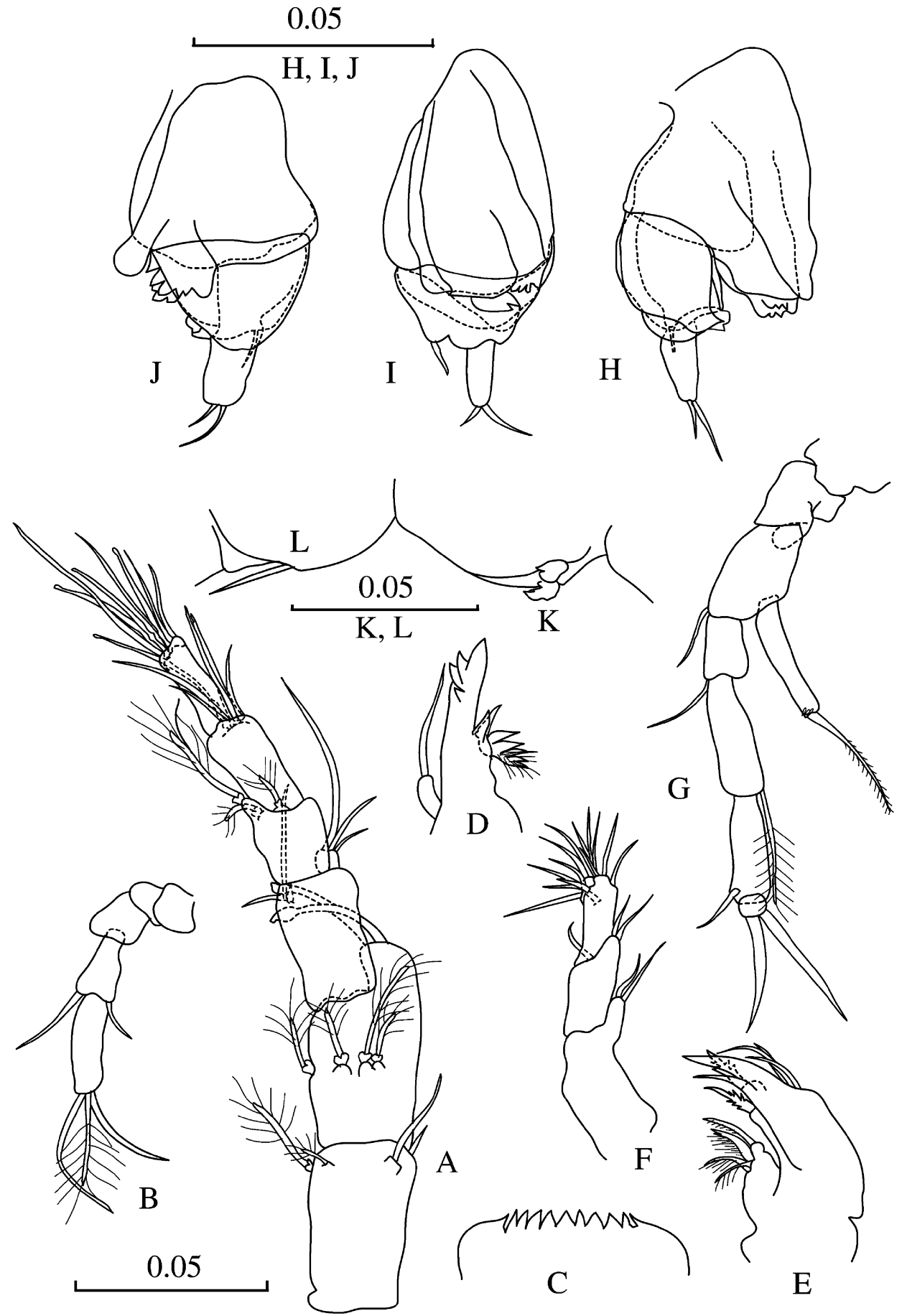

Figure 5. Hexabathynella sevillaensis n. sp., male. (A) Antennule (dorsal view); (B) antenna (dorsal view); (C) labrum; (D) mandible (lateral view); (E) maxillule (lateral view); (F) maxilla (lateral view); (G) thoracopod 1; (H) thoracopod 8 male (latero-external view); (I) thoracopod 8 male (frontal view); (J) thoracopod 8 male (latero-internal view); (K) thoracopod 8 female (ventro-lateral view); (L) pleopod female (ventro-lateral view). Scale bars in $\mathrm{mm}$. 

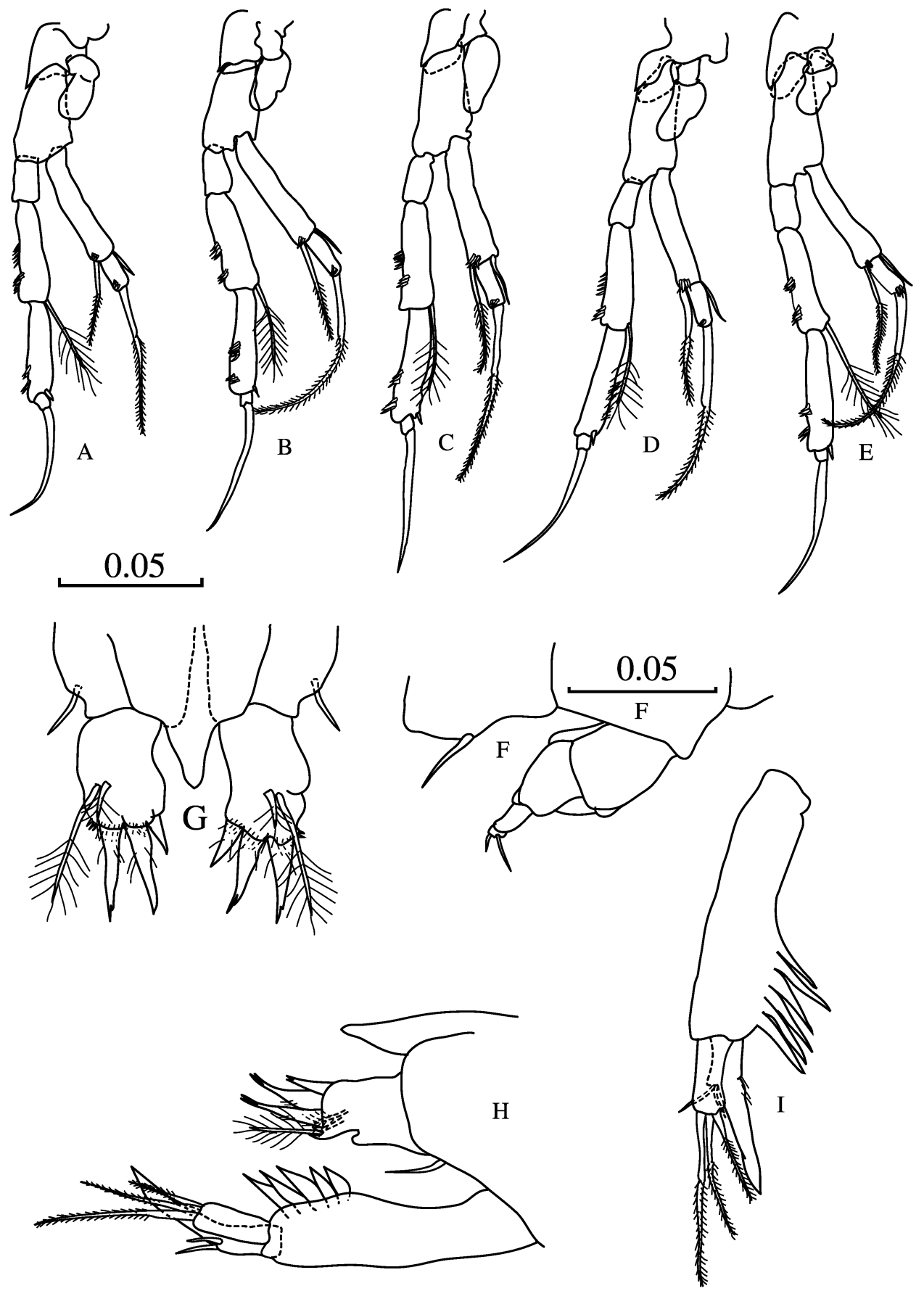

Figure 6. Hexabathynella sevillaensis n. sp. male. (A) Thoracopod 2; (B) thoracopod 3; (C) thoracopod 4; (D) thoracopod 5; (E) thoracopod 6; (F) thoracopod 8 male and pleopod (dorsal view); (G) pleotelson and furca (dorsal view); (H) pleotelson and furca female (lateral view); (I) uropod (latero-internal view). Scale bars in $\mathrm{mm}$. 
2003) (two and 15 males and no and 20 females, respectively). Fourteen specimens were studied. The holotype is a male and the type series contains 13 specimens (six females and seven males) (paratypes) (MNCN 20.04/5913).

\section{Diagnosis}

This species can be distinguished by the male antennal organ; the first four segments of the antennule are short and thick; the shape of the female thoracopod 8 is unique; the sympod has five spines of similar length, the exopod of the uropod has three setae, the endopod is twice longer than the exopod, and the setation on the endopod of the uropod (two short smooth setae of not very different length) is also unique.

\section{Description}

Body. Total length males $0.67-1.10 \mathrm{~mm}$ (holotype 1.04) and of females $1.00-1.20 \mathrm{~mm}$. Body elongated, almost cylindrical, segments progressively widening and lengthening towards posterior end of body. Head longer than wide.

Antennule (Figure 5A). With six thick, short segments; with sexual dimorphism in the second segment (antennal organ present in the male only); length of first three segments more than 1.5 times greater than the other three, segments 5 and 6 of similar length; segment 5 with three terminal aesthetascs and segment 6 with three subterminal aesthetascs; antennal organ in the male located on a protuberance on the inner distal angle, and in the apical zone it bears two long prolongations of equal length. The tip of these two prolongations widens and then narrows giving it a "teat-like" form.

Antenna (Figure 5B). Five segments, the distal two are the longest; segment 4 with two setae and last segment with two smooth setae and one plumose terminal seta; first three segments without setae.

Labrum (Figure 5C). With nine similar main teeth on ventral side, and one smaller lateral tooth at each end.

Mandible (Figure 5D). Pars incisiva with four strong teeth; pars molaris with six teeth, one strong and distal and the other five proximal, the two most proximal joined and with fine setae; mandibular palp not reaching beyond pars incisiva.

Maxillule (Figure 5E). Proximal endite with four claws (spines of different sizes); distal endite with four claws, two smooth and two with spines concentrated on distal end, and three smooth setae on outer distal margin.

Maxilla (Figure 5F). Three-segmented, with two setae on basal segment; segment 2 with three setae; segment 3 elongated with 13 setae.

Thoracopods. Thoracopods 1-6 (Figures 5G, 6A-E): length gradually increasing from pairs 1 to 4 , last two pairs similar in size; well-developed epipodite on pairs 2-6, almost exceeding half length of basipod. Thoracopod 1 (Figure $5 \mathrm{G}$ ): basipod with one lateral terminal seta; exopod one-segmented with one terminal barbed seta, and with one group of 
ctenidia at the distal margin of the exopod; endopod four-segmented: segment 1 with one smooth seta, 2 with one plumose seta, 3 with one small, smooth seta, terminal segment with two claws of slightly different length. Thoracopods 2-6 (Figure 6A-E): basipod without seta; exopod biarticulated, segment 1 with two terminal setae, one smooth, the other barbed, and segment 2 with a terminal barbed seta (ctenidia at the distal margin of the segments); endopod four-segmented, segment 1 short and without setae, 2 with two groups of lateral ctenidia, and one plumose seta, 3 with one tiny seta and with two groups of lateral ctenidia and segment 4 with one strong claw. Thoracopod 8 male (Figures 5J-H, $6 \mathrm{~F})$ : compact, twice as long as wide; endopod long and thick with two smooth setae of different length; basal segment of the protopod massive and almost reaching end of basipod, free side with teeth; basipod almost square ending in a point, with one seta; small, rounded exopod. Thoracopod 8 female (Figure 5K): small, almost cylindrical with two small terminal teeth. First pleopod (Figures 5L, 6F) as a simple seta on the pleon.

Dorsal margin of the pleotelson (Figure 6G, H). Anal operculum very pronounced, almost as long as furca; one smooth seta on lateral side.

Uropod (Figure 6H, I). Sympod almost twice length of the endopod and almost four times as long as wide, with seven spines of equal length, which are located on the second half; endopod twice length of the exopod, with a rim of ctenidia and with two outer dorsal small, smooth setae (they do not reach tip of the endopod); exopod with three terminal barbed setae of different lengths (see Figure $6 \mathrm{H}, \mathrm{I}$ ).

Furca (Figure 6G, H). With three similar smooth spines and two dorsal plumose setae, one long and one short.

\section{Etymology}

This species is named after the province in Sevilla where the genus Hexabathynella was found for the first time in a cave.

\section{Remarks}

The new species presents a series of unique characters within the genus (see Table IV). The antennal organ is unique; although the aspect of the two structures which form the antennal organ is comparable (except the tip) with H. nicoleiana Camacho, 1986 and H. otayana Cho, 2001, the size of the protuberance is different, longer than in those two species. Besides, the tip of the prolongations is normally sharply pointed in almost all species and in the new species it is different to both (see Figure 5A). In the new species the segments 5 and 6 are long, while in all other species of the genus all segments are short and wide, particularly 5. Hexabathynella sevillaensis $\mathrm{n}$. sp. is the only species in the genus with 11 teeth on the labrum; the setal formula of the maxilla is unique: $2 / 3 / 13$ setae on the three segments, respectively; the distal segment of the the maxillule has four claws like H. otayana (see Table IV), but in this species all are smooth and the new species has two denticulated and two smooth claws; the sympod of the uropod consists of six spines all similar in size. In all other species in this genus the distal spines are longest. The combination of setae on the exopod and endopod of the uropod (three barbed and two small and smooth setae, respectively) is similar to that of $H$. knoepfleri (Coineau, 1965). 
Table IV. Taxonomic characters of the different species of the Hexabathynella Schminke, 1972 genus.

\begin{tabular}{|c|c|c|c|c|c|c|c|c|c|c|c|c|c|c|c|c|c|c|c|}
\hline & \multicolumn{19}{|c|}{ Species of the Hexabathynella Schminke, 1972 genus } \\
\hline & 1 & 2 & 3 & 4 & 5 & 6 & 7 & 8 & 9 & 10 & 11 & 12 & 13 & 14 & 15 & 16 & 17 & 18 & 19 \\
\hline \multicolumn{20}{|l|}{ Antennal organ } \\
\hline Protuberance & $\operatorname{Pr}$ & $\operatorname{Pr}$ & $\operatorname{Pr}$ & A & $\operatorname{Pr}$ & $\operatorname{Pr}$ & - & $\operatorname{Pr}$ & $\operatorname{Pr}$ & $\operatorname{Pr}$ & $\operatorname{Pr}$ & A & $\operatorname{Pr}$ & $\operatorname{Pr}$ & $\operatorname{Pr}$ & $\operatorname{Pr}$ & A & A & $\operatorname{Pr}$ \\
\hline Prolongations & $\operatorname{Sim}$ & $\operatorname{Sim}$ & $\operatorname{Sim}$ & $\operatorname{Sim}$ & $\operatorname{Sim}$ & $\operatorname{Sim}$ & - & Dif & Dif & Dif & Dif & $\operatorname{Sim}$ & $\operatorname{Sim}$ & $\operatorname{Sim}$ & $\operatorname{Sim}$ & Sim & $\operatorname{Sim}$ & Dif & Sim \\
\hline \multicolumn{20}{|l|}{ Labrum } \\
\hline No. of teeth & 10 & 10 & 10 & 10 & 10 & 10 & 10 & 10 & 13 & 12 & 14 & 10 & 10 & 10 & 10 & 10 & 12 & 10 & 11 \\
\hline \multicolumn{20}{|l|}{ Mandible } \\
\hline No. of teeth on pars incisiva & $4-5$ & $3-5$ & 4 & 5 & 4 & 4 & 4 & 4 & 4 & 4 & 4 & 4 & 4 & 4 & 4 & 4 & 4 & 4 & 4 \\
\hline No. of teeth on pars molaris & 5 & 5 & 5 & 4 & 5 & 5 & 5 & 5 & 5 & 5 & 5 & 5 & 5 & 5 & 5 & 6 & 5 & 6 & 6 \\
\hline Distal spine modified & $\mathrm{Y}$ & $\mathrm{Y}$ & $\mathrm{N}$ & $\mathrm{N}$ & $\mathrm{Y}$ & $\mathrm{Y}$ & $\mathrm{Y}$ & $\mathrm{N}$ & $\mathrm{N}$ & $\mathrm{N}$ & $\mathrm{N}$ & $\mathrm{N}$ & $\mathrm{N}$ & $\mathrm{N}$ & $\mathrm{N}$ & $\mathrm{N}$ & $\mathrm{N}$ & $\mathrm{N}$ & $\mathrm{N}$ \\
\hline \multicolumn{20}{|l|}{ Maxillule } \\
\hline No. of teeth on distal endite & 4 & 4 & 4 & 5 & 4 & 5 & 5 & 7 & 6 & 6 & 6 & 5 & 5 & 5 & 5 & 5 & 4 & 7 & 4 \\
\hline No. of teeth on proximal endite & 3 & 3 & 3 & 3 & 4 & 4 & 4 & 4 & 4 & 4 & 4 & 3 & 3 & 3 & 3 & 3 & 3 & 4 & 4 \\
\hline \multicolumn{20}{|l|}{ Maxilla } \\
\hline No. of setae on segment 2 & 4 & 4 & 4 & 4 & 4 & 4 & 4 & 3 & 4 & 4 & 4 & 3 & 3 & 3 & 3 & 3 & 2 & 4 & 3 \\
\hline No. of setae on segment 3 & 13 & 10 & 12 & 14 & 13 & 14 & 14 & 12 & 14 & 12 & 13 & 12 & 12 & 12 & 12 & 12 & 12 & 10 & 13 \\
\hline \multicolumn{20}{|l|}{ Thoracopod 1 endopod } \\
\hline No. of setae on segment 2 & 1 & 1 & 1 & 1 & 1 & 1 & 1 & 1 & 1 & 1 & 1 & 1 & 1 & 1 & 1 & 1 & 2 & 2 & 1 \\
\hline No. of setae on segment 4 & 2 & 3 & 2 & 2 & 2 & 2 & 2 & 2 & 3 & 3 & 3 & 2 & 2 & 2 & 2 & 2 & 3 & 3 & 2 \\
\hline \multicolumn{20}{|l|}{ Thoracopod 8} \\
\hline Size & $M$ & M & $M$ & $M$ & $M$ & S & $M$ & $S$ & S & S & $S$ & $S$ & M & M & $S$ & $S$ & A & $M$ & $M$ \\
\hline \multicolumn{20}{|l|}{ Uropod } \\
\hline No. of spines on sympod & $5+1$ & $2+1$ & $6+1$ & $1+1$ & $1+1$ & $1+1$ & $2+1$ & $3+1$ & $4+1$ & $7+1$ & $3+1$ & $4+1$ & $4+1$ & $3+1$ & $4+1$ & $3+1$ & $5+1$ & $7+1$ & 6 \\
\hline No. of setae on exopod & $3 \mathrm{~B}$ & $3 \mathrm{~B}$ & $3 \mathrm{~B}+1 \mathrm{P}$ & $3 \mathrm{~B}$ & $2 \mathrm{~B}$ & $2 \mathrm{~B}$ & $2 \mathrm{~B}$ & $1+1 \mathrm{~B}$ & $1+1 \mathrm{~B}$ & $2+1 B$ & 2 & 1 & $1+1 \mathrm{P}$ & $1+1 \mathrm{P}$ & $1+1 \mathrm{P}$ & $1+1 P$ & 2 & $2 \mathrm{~B}$ & $3 \mathrm{~B}$ \\
\hline No. of setae on endopod & $1+1 \mathrm{P}$ & $3 \mathrm{P}$ & $2 \mathrm{~B}+1 \mathrm{P}$ & 2 & 3 & $2+1 \mathrm{P}$ & $2+1 \mathrm{P}$ & 2 & 2 & 3 & 2 & 2 & 1 & 1 & 1 & 1 & 3 & 3 & 2 \\
\hline \multicolumn{20}{|l|}{ Pleotelson } \\
\hline No. of setae & 1 & 1 & 1 & 1 & 1 & 1 & 1 & 1 & 2 & 2 & 2 & 1 & 1 & 1 & 1 & 1 & 2 & - & 1 \\
\hline Anal operculum & $\mathrm{L}$ & $S$ & XL & $M$ & $M$ & $\mathrm{~L}$ & $\mathrm{~L}$ & $S$ & $M$ & $S$ & $S$ & $S$ & - & M & - & - & $M$ & - & $\mathrm{L}$ \\
\hline
\end{tabular}

1, H. nicoleiana Camacho, 1986; 2, H. minuta (Noodt and Galhano, 1969); 3, H. valdecasasi Camacho, 2004; 4, H. knoepffleri (Coineau, 1965); 5, H. otayana Cho, 2001; 6, H. hessleri Cho, 2001; 7, H. muliebris Cho, 2001; 8, H. pauliani (Delamare Deboutteville, 1953); 9, H. decora Schminke, 1973; 10, H. aotearoae Schminke, 1973; 11, H. halophila Schminke, 1972; 12, H. hebrica (Cvetkov and Petrova, 1964); 13, H. longiappendiculata (Cvetkov, 1970b); 14, H. tenera (Cvetkov, 1968); 15, H. breviappendiculata (Cvetkov, 1970a); 16, H. nestica (Cvetkov, 1970a); 17, H. szidati (Noodt, 1965); 18, H. paranaensis (Jakobi, 1972); 19, H. sevillaensis n. sp. B, barbed; P, plumose; S, small; M, medium; L, large; XL, extra-large; Pr, present; A, absent; Sim, similar; Dif, different. 
The female thoracopod 8 is not significantly reduced in size, as occurs in many other species (H. nicoleiana, H. minuta (Noodt and Galhano, 1969), H. valdecasasi Camacho, 2004, H. knoepffleri, H. paranaensis (Jakobi, 1972), H. tenera (Cvetkov, 1968), H. longiappendiculata (Cvetkov, 1970b), H. otayana and H. muliebris Cho, 2001) (see Table IV). The mandible of the new species is similar to $H$. nestica (Cvetkov, 1970a) and $H$. paranaensis.

The thoracopod 8 male is relatively large for the medium size of the species (as is also the case in $H$. nicoleiana); the relative proportions of the lobes resemble only $H$. minuta (this is the species which is geographically closest to the new species), but H. minuta is a small species with a small and more square male thoracopod 8 .

The presence of a single seta near the ventro-lateral base of the furcal rami of the pleotelson is shared with all European species, the three north American species ( $H$. otayana, $H$. muliebris and $H$. hessleri Cho, 2001), and H. pauliani (Delamare Deboutteville, 1953) from Madagascar.

Hexabathynella sevillaensis $\mathrm{n}$. $\mathrm{sp}$. is a medium-sized species, as are the majority of the species in the genus except for H. hebrica (Cvetkov and Petrova, 1964) which is the largest and $H$. minuta, $H$. pauliani and $H$. tenera which are small.

Some of the characters exhibited by the new species are present in other species in the genus (see Table IV), but the combination of all of them is unique to the new species.

\section{Distribution}

The map in Figure 7 shows the distribution of the three new species and also the distribution of all the species of the genus Hexabathynella found on the Iberian Peninsula.

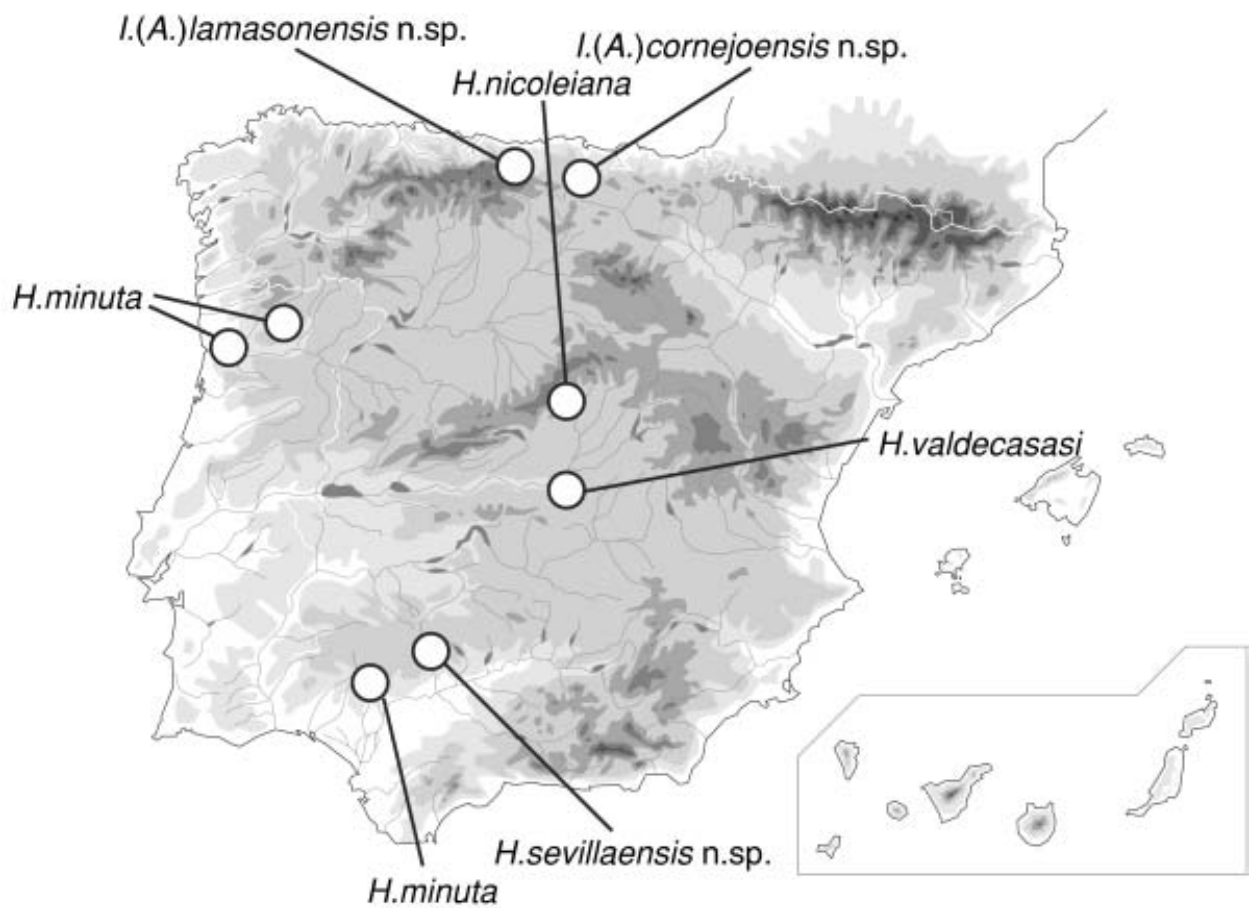

Figure 7. Distribution of the new species of Iberobathynella (Asturibathynella) and all species of Hexabathynella on the Iberian Peninsula. 
The two new species of Iberobathynella were found in the north of Spain where most of the species of the subgenus to which the two new species belong occur (Camacho 2003b, 2003c). To date, on the Iberian Peninsula 20 species of this endemic genus are known. All of these species are distributed in the north and in the west; in the south and in the east it has only been found in two localities. This region, the Mediterranean region, is occupied by Paraiberobathynella Camacho and Serban, 1998 and the centre of the Iberian Peninsula by Hexaiberobathynella Camacho and Serban, 1998, also belonging to the Iberobathynellini (Camacho and Serban 1998; Camacho 2003b, 2003c).

Hexabathynella sevillaensis $\mathrm{n}$. $\mathrm{sp}$. occurs in the south, close to the locality where Hexabathynella minuta is found in Spain. The other two species of this genus known in Spain, H. nicoleiana and $H$. valdecasasi Camacho, 2004, occur in the centre. This new species is the fourth species of Hexabathynella to be found on the Iberian Peninsula (in six localities), making Spain the second country in the world for diversity in this cosmopolitan genus (Bulgaria is the first, with five species) (Camacho 2003a, 2004).

\section{Acknowledgements}

We gratefully acknowledge C. Puch, F. Molinero, J. Robador, A. De Juan, F. Lázaro, A. G. Valdecasas and J. Rodriguez, who helped us in different ways. We thank Mark Creb who helped us with the English translations. This work was supported by projects REN20002040 GLO, EVK2-CT-2001-00121 (European Projects PASCALIS) and Convenio Junta de Castilla y León and CSIC.

\section{References}

Braga JM. 1949. Un Bathynellidae (Crust. Syncarida) du Portugal (Parabathynella lusitanica n. sp.). Publicaçoes do Instituto de Zoologia "Dr. Augusto Nobre" 40:1-15.

Braga JM. 1960. Sur une Parabathynella (Crust. Syncarida) nouvelle du Portugal. Publicaçoes do Instituto de Zoologia "Dr. Augusto Nobre" 75:9-22.

Camacho AI. 1986. A new species of the genus Hexabathynella (Syncarida, Bathynellacea, Parabathynellidae) from Spain. Bijdragen tot de Dierkunde 56(1):123-131.

Camacho AI. 1987. A new subterranean syncarid (Crustacea) from Spain: Iberobathynella imuniensis n. sp. (Bathynellacea, Parabathynelidae). Archiv für Hydrobiologie 111(1):137-149.

Camacho AI. 1989. A new species of the "mateusi" group: Iberobathynella ortizi sp. n. (Crustacea, Syncarida, Parabathynellidae). Zoologica Scripta 18(3):405-410.

Camacho AI. 1992. Sampling the subterranean biota cave (aquatic environment). In: Camacho AI, editor. The natural history of biospeology Madrid: CSIC. 681 p. (Monografia del Museo Nacional de Ciencias Naturales de Madrid; 7).

Camacho AI. 2003a. Historical biogeography of Hexabathynella, a cosmopolitan genus of groundwater Syncarida (Crustacea, Bathynellacea, Parabathynellidae). Biological Journal of the Linnean Society 78:457-466.

Camacho AI. 2003b. Four new species of groundwater crustaceans (Syncarida, Bathynellacea, Parabathynellidae) endemic to the Iberian Peninsula. Journal of Natural History 37:2885-2907.

Camacho AI. 2003c. An overview of the distribution of the Parabathynellidae (Crustacea, Syncarida, Bathynellacea) on the Iberian Peninsula and Balearic Islands. Graellsia 59(1):63-78.

Camacho AI. 2004. An overview of Hexabathynella (Crustacea, Syncarida, Parabathynellidae) with the description of a new species. Journal of Natural History 38:1249-1261.

Camacho AI, Bello E, Estabrook GF. 1997. A statistical approach to the evaluation of characters to estimate evolutionary relationships among the species of the aquatic subterranean genus, Iberobathynella (Crustacea, Syncarida). Biological Journal of the Linnean Society 60:221-241.

Camacho AI, Coineau N. 1987. Un nouveau représentant du genre Iberobathynella Schminke en Espagne: I. rouchi n. sp. (Syncarida, Bathynellacea). Remarques phylogénétiques et paléobiogéographiques. Stygologia 3(2):125-137. 
Camacho AI, Serban E. 1998. Tribu des Iberobathynellini nov. Diagnoses des taxa nouveaux (Parabathynellidae, Bathynellacea, Podophallocarida). Travaux de l'Institut de Spéologie Emile Racovitza 34(1995):15-75.

Camacho AI, Serban E. 2000. Revisión del grupo Iberobathynella (Iberobathynella) Schminke, 1973 (Crustacea, Syncarida, Parabathynellidae) endémico de la Península Ibérica. Graellsia 56:35-48.

Camacho AI, Serban E, Guil N. 2000. Phylogenetical review and biogeographic remarks on the interstitial and subterranean freshwater iberobathynell (Crustacea, Syncarida, Parabathynellidae). Journal of Natural History 34:563-585.

Cho JL. 2001. Phylogeny and zoogeography of three new species of the genus Hexabathynella (Crustacea, Malacostraca, Bathynellacea) from North America. Zoologica Scripta 30(2):145-157.

Coineau N. 1965. Recherches sur la faune des Iles Méditerranéennes. I. Le genre Parabathynella (Crust. Syncar.) en Corse. Vie Milieu 15:993-1005.

Cvetkov L. 1968. Nouvelle forme du groupe de Parabathynella hebrica Cvetkov and Petrova (Crust. Bathynellidae). Comptes Rendus de l'Acadèmie Bulgare des Sciences 21:55-58.

Cvetkov L. 1970a. Deux nouvelles èspeces de Parabathynella (Crust. Bathynellacea) en Bulgarie du sud. Comptes Rendus de l'Acadèmie Bulgare des Sciences 23(5):575-578.

Cvetkov L. 1970b. Parabathynella longiappendiculata n. sp.: la cinquième nouvelle espèce de Parabathynella en Bulgarie du sud. Comptes Rendus de l'Académie Bulgare des Sciences 23(11):1409-1411.

Cvetkov L, Petrova A. 1964. Un nouveau représentant des Syncarides, Parabathynella hebrica n. sp. Bulletin de l'Institut de Zoologie et Musée 16:191-200.

Delamare Deboutteville C. 1953. Une espèce nouvelle de Parabathynelle à Madagascar: Parabathynella pauliani. Diagnose préliminaire. Vie Milieu 4:748.

Galhano MH. 1970. Contribuçao para o conhecimiento de fauna intersticial em Portugal. Parabathynella lusitanica valbonensis ssp. n. Publicaçoes do Instituto de Zoologia "Dr. Augusto Nobre” 110:77-82, 148-153.

Guil N, Camacho AI. 2001. Historical biogeography of Iberobathynella (Crustacea, Syncarida, Bathynellacea), an aquatic subterranean genus of Parabathynellids, endemic to the Iberian Peninsula. Global Ecology and Biogeography 10:487-501.

Jakobi H. 1972. Parabathynella paranaensis sp. n. (Syncarida, Bathynellacea) aus der Bucht von Paranaguá (Brasilien). Studies on the Neotropical Fauna 7:229-237.

Noodt W. 1965. Crustacea subterranea aus Argentinien. Beitrage Neotropische Fauna 4:84-129.

Noodt W, Galhano MH. 1969. Studien and Crustacea subterranea (Isopoda, Syncarida, Copepoda) aus dem Norden Portuga. Publicaçoes do Instituto de Zoologia "Dr. Augusto Nobre" 107:9-75.

Schminke HK. 1972. Hexabathynella halophila gen. n., sp. n. und die Frage nach der marinen Abkunft der Bathynellacea (Crustacea: Malacostraca). Marine Biology 15:282-287.

Schminke HK. 1973. Evolution, System und Verbreitungsgeschichte der Familie Parabathynellidae (Bathynellacea, Malacostraca), Akademie der Wissenschaften und der Literatur Mainz, MathematischNaturwissenschaftliche Klasse. Mikrofauna des Meeresboden 24:1-192.

Serban E, Comas i Navarro JC. 1978. Contribution à la connaissance du genre Iberobathynella Schminke: I. asturiensis n. sp. et I. espaniensis n. sp., nouvelles espèces d'Espagne (Bathynellacea, Parabathynellidae). Travaux de 1'Institut de Spéologie "Emile Racovitza” 17:13-37. 